GLOBAL JOURNAL OF ENGINEERING RESEARCH VOL 12, 2013: 63-68

\title{
EMPIRICAL MODEL FOR PREDICTING RATE OF BIOGAS PRODUCTION
}

\author{
A. A. ADAMU AND E. O. ALUYOR \\ (Received 27, May 2013; Revision Accepted 16, July 2013)
}

\begin{abstract}
Rate of biogas production using cow manure as substrate was monitored in two laboratory scale batch reactors (13 liter and 108 liter capacities). Two empirical models based on the Gompertz and the modified logistic equations were used to fit the experimental data based on non-linear regression analysis using Solver tool in Microsoft Excel. The 13-liter reactor was used in Experiments1 \& 2 and in Experiment 3 the 108-liter reactor was used. In all the three experiments, Gompertz model gave a better goodness of fit than the modified Logistic model. The cross correlation coefficients for experiment 3 are 0.9972 and 0.9965 for Gompertz and Modified Logistic models respectively. Atomic absorption spectroscopy (AAS) analysis of the biogas indicates that its methane content is above $70 \%$ in both reactors.
\end{abstract}

KEYWORDS: Empirical model, Non-linear regression, biogas production, cow manure.

\section{INTRODUCTION}

Biogas is a Gas obtained by anaerobic decomposition of organic wastes such as vegetables, plants, crop residues, human and animal wastes, and consists of methane as a major component with impurities such as $\mathrm{CO}_{2}$, $\mathrm{N}_{2}, \mathrm{H}_{2}$, and $\mathrm{H}_{2} \mathrm{~S}$. Biogas reactors have received considerable attention in recent times because of the need to develop an alternative source of energy which is renewable in order to reduce the dependence on fossil fuels which are responsible for global warming. Extensive studies on the biochemistry and operational characteristics of biogas reactors have led to development of various types of biogas reactors, Batch, sequencing batch, and continuous reactors. To develop a reliable design of biogas reactor and assess its performance, appropriate mathematical models describing the process is necessary. There are numerous mathematical models in literature such as models for calculating biogas production based on stoichiometry and models based on reaction kinetics which also takes product inhibition, substrate limiting etc. into consideration.

Gerber and Span (2008) presented a comprehensive review on models available for biogas reactor. However, the complexity of biogas reactors (in terms of process variables), the presence of micro-colonies, the interaction between different microbial species, and the complex nature of substrates complicates such modeling. Basic knowledge of the phenomena is insufficient to build a mechanistic model. In this case, an empirical model or a statistical analysis can be formulated to elucidate basic mechanisms underlying this complex system and thus providing better guidance in process design and control. The empirical models parameters are established through non-linear regression methods. The most widely used empirical model used for predicting rate of biogas production is the Gompertz and modified Gompertz equation (Budiyono and others, 2010).

In this study, the rate of Biogas production in the digester would be analyzed using Gompertz and modified Logistic models.

A. A. Adamu, Petroleum and Natural Gas Processing Department, Petroleum Training Institute, P.M.B. 20, Effurun Delta state-Nigeria.

E. O. Aluyor, Department of Chemical Engineering University of Benin, Benin City Edo state Nigeria. 
2.

BIOGAS REACTOR MODELS

\section{Kinetic Models}

Several kinetics models have been developed to describe the anaerobic fermentation process. Monod showed a hyperbolic relationship between the exponential microbial growth rate and substrate concentration. In this model, the raw kinetic parameters, namely, micro organisms growth rate and half velocity constant are deterministic in a nature, and these predict the conditions of timing of maximum biological activity and its cessation this model can be used to determine the rate of substrate utilization $\left(r_{s}\right)$ using the equation:

$$
\mathrm{r}_{\mathrm{s}}=\frac{\mu_{\mathrm{m}} \mathrm{XS}}{\mathrm{Y}\left(\mathrm{K}_{\mathrm{s}}+\mathrm{S}\right)}
$$

The Monod model suffers from the drawback that one set of kinetic parameters are not sufficient to describe biological process both for short and long retention times and that kinetic parameters cannot be obtained from complex substrates. To alleviate limitations of the Monod model while retaining its advantages some other models have been developed which attempt to describe kinetics of substrate fermentation in terms of several parameters. Gupta and others (2009) presented a simple first order kinetic model based on substrate utilization to predict rate of biogas production.

\section{Empirical Models}

Researchers on Biogas have attempted to use several models to fit empirical data, the most widely used model is the Gompertz model given by the following equation;

$$
\mathrm{v}=\mathrm{A} \exp \left[-\exp \left\{\frac{\mathrm{R}_{\text {max }} \mathrm{e}}{\mathrm{A}}(\lambda-\mathrm{t})+1\right\}\right]
$$

And the modified Gompertz equation also called Gompertz-T equation given as;

$$
\mathrm{v}=(\delta \mathrm{t}+\mathrm{A}) \exp \left[-\exp \left\{\frac{\mathrm{R}_{\max } \mathrm{e}}{(\delta \mathrm{t}+\mathrm{A})}(\lambda-\mathrm{t})+1\right\}\right]
$$

The Modified Gompertz equation and the Logistic function models have been used with experimental data from the anaerobic digesters (Donoso-Bravo and others, 2009).
3. MODEL DEVELOPMENT

Goudriaan and Monteith in 1990 derived a single equation (the expolinear equation) from logistic function to represent both the exponential and linear phases of crop growth (Yin and others, 2003) (see Equation (4);

$$
\mathrm{W}=\frac{\mathrm{c}_{\mathrm{m}}}{\mathrm{r}_{\mathrm{m}}} \ln \left[1+\mathrm{e}^{\mathrm{r}_{\mathrm{m}}\left(\mathrm{t}-\mathrm{t}_{\mathrm{o}}\right)}\right]
$$

Equation (4) can be applied to Biogas production rate after slight modification in the definition of terms.

$$
\mathrm{v}=\frac{\mathrm{c}_{\mathrm{m}}}{\mathrm{k}} \ln \left[1+\mathrm{e}^{\mathrm{k}(\mathrm{t}-\lambda)}\right]
$$

\section{MATERIALS AND METHODS}

Inoculation: Seeding sludge was taken from a waste dump near Petroleum and Natural Gas Processing Department Petroleum Training Institute Effurun, Delta State Nigeria.

Substrate: Fresh cow manure obtained from Effurun Cattle market, was mixed with water in ratio $1: 1$ to form slurry which was then inoculated with the seeding sludge (inoculums) at $50 \mathrm{ml} /$ liter. In experiments $1 \& 2,2.5 \mathrm{~kg}$ of the manure was used to form 6 liters of slurry which was loaded into a 13-liter digester. While in experiment 3 , $27.5 \mathrm{~kg}$ of manure was used to form 50 liters of slurry which was loaded into a 108-liter digester. The three experiments were conducted at different times of the year. The biogas produced was monitored through a pressure gauge, over a period of one month. The pressure was converted to volume using ideal gas equation and data fitted into Gompertz and modified Logistic models using Non-linear regression analysis with Solver tool in Microsoft Excel. The biogas produced was analyzed at WRPC using Atomic absorption spectrophotometer (ASXLFID). Also the chemical oxygen demand COD of the substrate was determined using ASTM D1252-95.

\section{RESULTS AND DISCUSSION}

The COD of the substrate was found to be $3.04 \times 10^{6} \mathrm{mg} / \mathrm{L}$. Figure 1 through Figure 4 shows the graphical representation of the results obtained and Table 1 shows the goodness of fit for the models tested. 


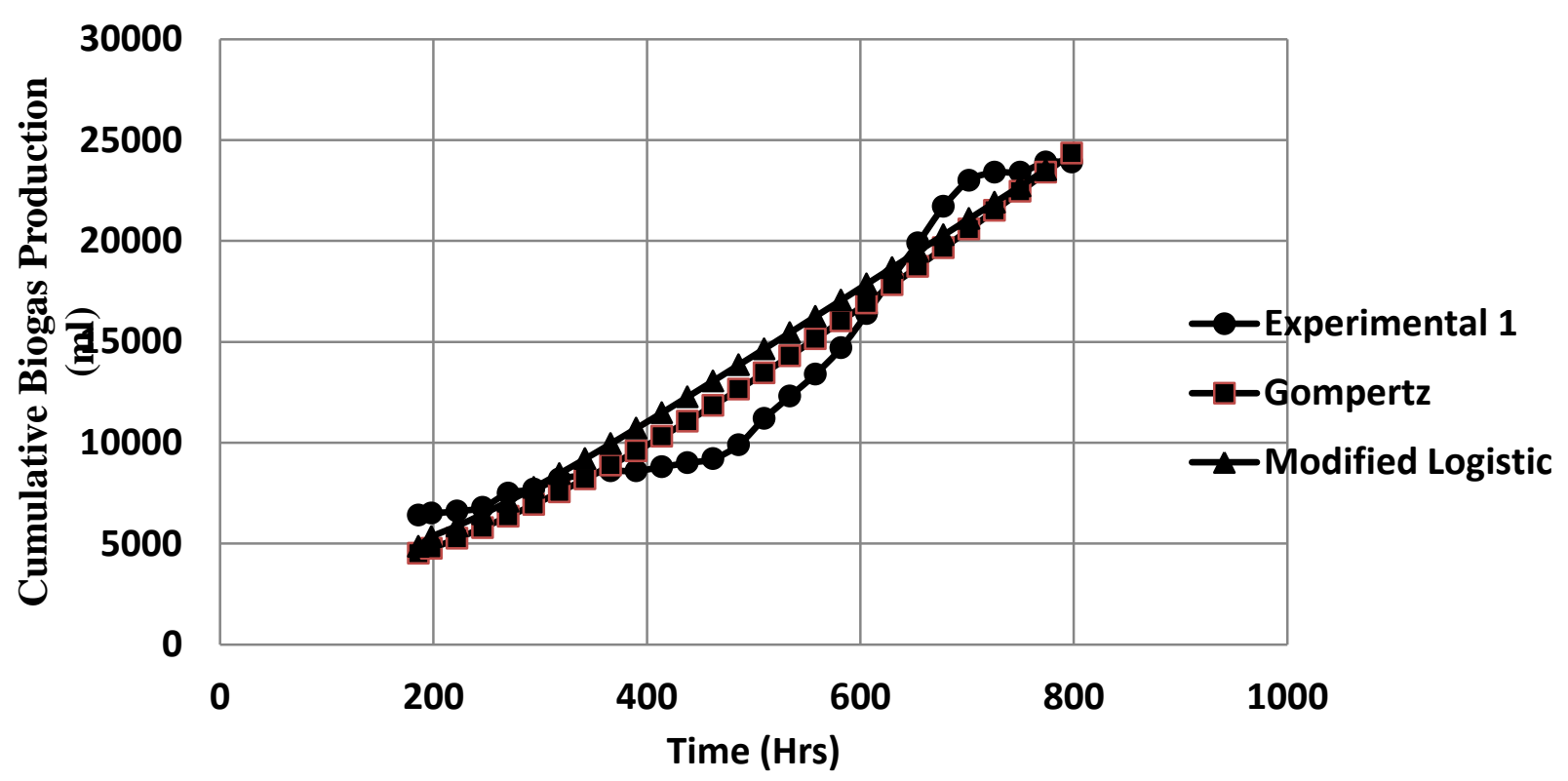

Figure 1: Cumulative Biogas Production for the 13-liter digester ( Experiment 1)

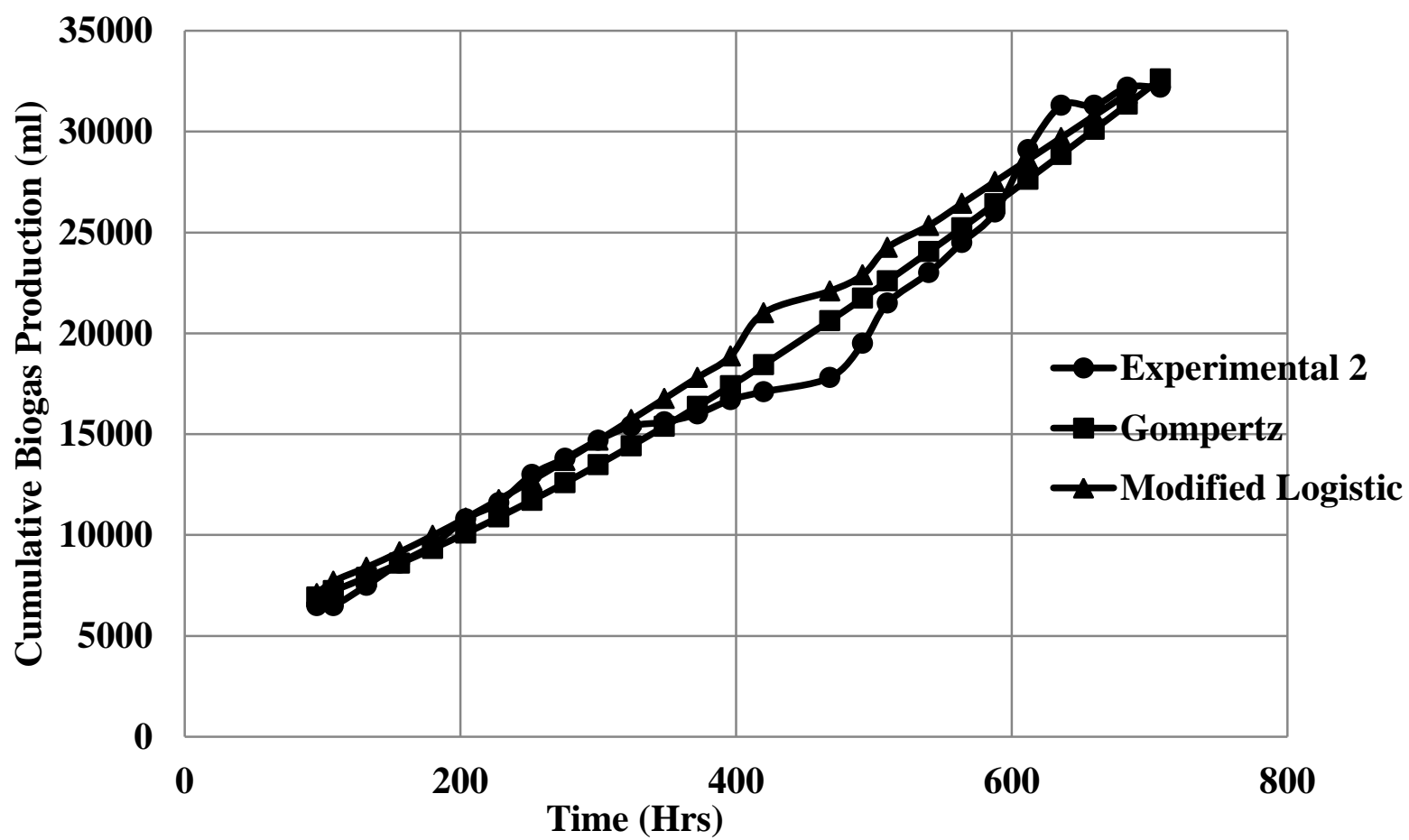

Figure 2: Cumulative Biogas Production for the 13-liter digester ( Experiment 2) 


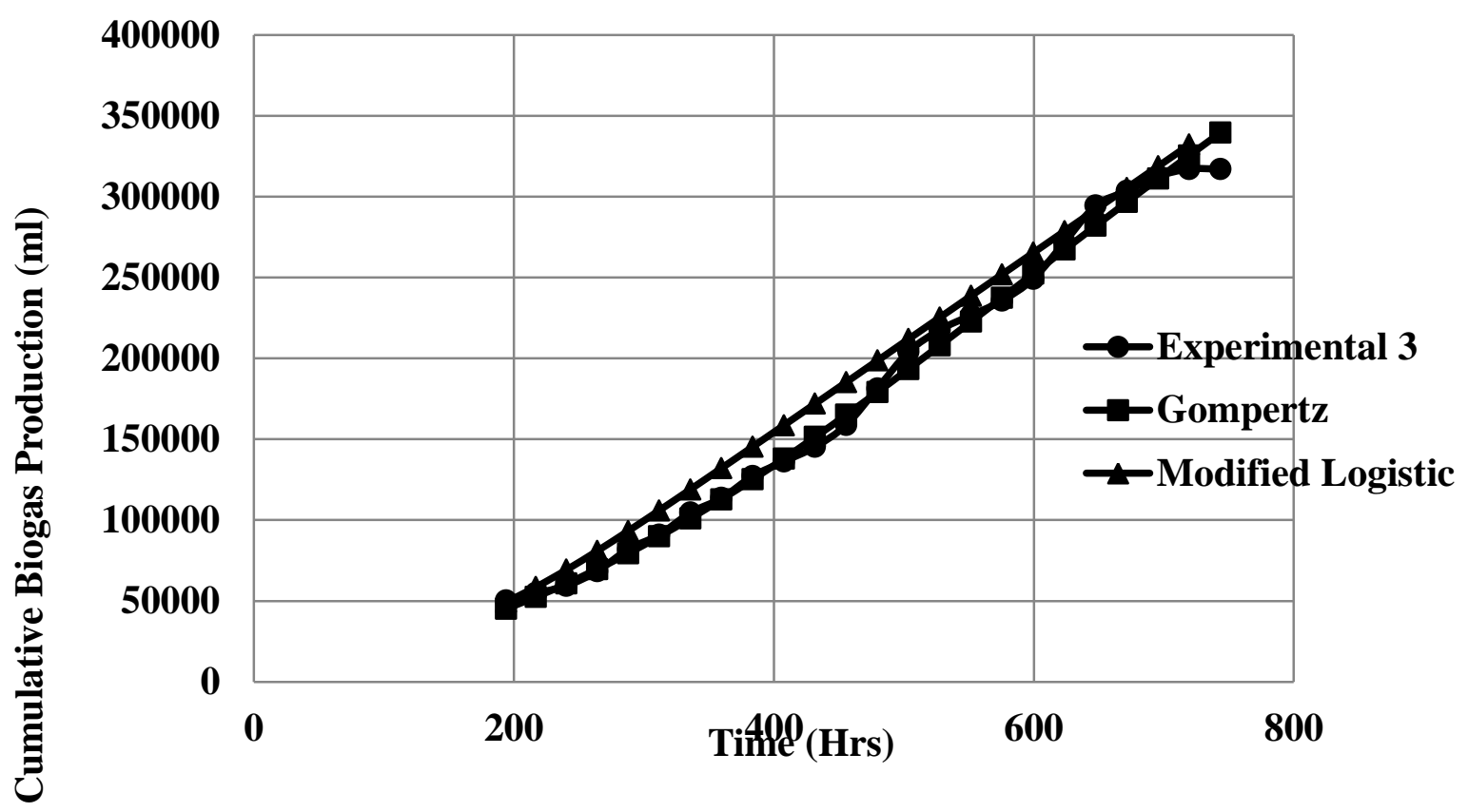

Figure 3: Cumulative Biogas Production for the 108-liter digester ( Experiment 3)

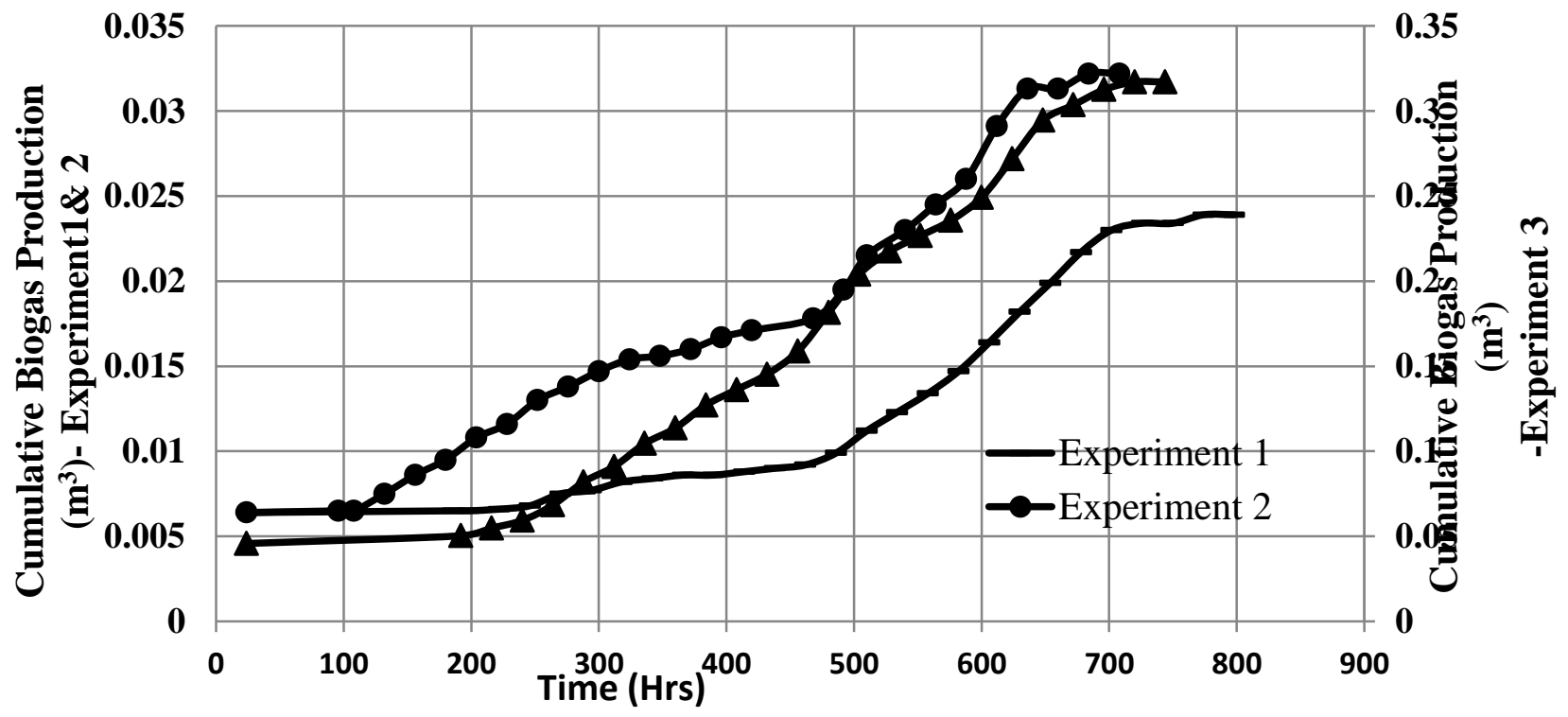

Figure 4: Comparative results for the three experiments

Table 1: Goodness of fit for the three experiments.

\begin{tabular}{|l|l|l|}
\hline \multicolumn{3}{|l|}{ Cross Correlation coefficient } \\
\hline Experiment & Gompertz Model & Modified Logistic Model \\
\hline 1 & 0.9698 & 0.9613 \\
\hline 2 & 0.9894 & 0.9863 \\
\hline 3 & 0.9972 & 0.9965 \\
\hline
\end{tabular}




\section{DISCUSSIONS}

In all the three experiments, Gompertz model seem to give a better goodness of fit than the modified logistic model. The plot of cumulative biogas against time shows that all the three curves are similar in shape with a marked difference quantitatively between data in Experiments 1 and 2, this may be due to difference in season for which the experiments were conducted.

\section{CONCLUSION \& RECOMMENDATION}

Based on the results obtained, Gompertz model will serve as a better empirical model than the modified Logistic model for predicting rate of biogas production.

Further work is required to determine the effect of seasonal variation on predicting rate of biogas production using these models.

\section{REFERENCES}

Gerber, M and Span, R., 2008. An analysis of available mathematical models for anaerobic digestion of organic substances for production of biogas, International Gas Union Research Conference.
Budiyano, I. N and Widiasa, S., 2010. "The kinetic of Biogas production rate from cattle manure in batch mode", International Journal of Chemical \& Biological Engineering, 3, (1): p 39-49.

Gupta, A., Chandra, R., Subbarao, P. M. V and

Vijay, V. K., 2009. "Kinetics of Batch Biomethanation Process of Jatropha and Pongamia Oil Cakes and their Codigested Substrates", Journal of Scientific and Industrial Research, 68, July, p 624-629.

Donoso-Bravo, A., Pérez-Elvira, S. I and FdzPolanco, F., 2009. "Application of simplified models for anaerobic biodegradability tests. Evaluation of pre-treatment processes", Chemical Engineering Journal 160, Issue 2, June, p 607-614.

Goudriaan, J and Monteith, J. L., 1990. "A mathematical for crop growth based on light interception and leaf area expansion", Annals of Botany 66, p 695701.

Yin, X., Goudriaan, J., Lantinga, E. A., Vos, J and Spiertz, H. J., 2003. "A Flexible Sigmoid Function of Determinate Growth", Annals of Botany 91, Issue 3, p 361371. 


\section{APPENDIX}

\section{Nomenclature}

$A=$ Biogas production potential $(\mathrm{mL})$.

$\mathrm{C}_{\mathrm{m}}=$ Maximum biogas production rate in the linear phase $(\mathrm{mL} / \mathrm{hr})$.

$\mathrm{K}_{\mathrm{s}}=$ half velocity constant $(\mathrm{mgCOD} / \mathrm{L})$

$\mathrm{k}=$ Rate constant for biogas production $\left(\mathrm{hr}^{-1}\right)$.

$\mathrm{R}_{\max }=$ Maximum biogas production rate (mL/gVSS.hr).

$r_{\mathrm{m}}=$ maximum relative production rate in the exponential phase $(\mathrm{g} / \mathrm{hr})$

$\mathrm{S}=$ limiting substrate concentration (mgCOD/L)

$\mathrm{t}=$ Cumulative time for biogas production (hr).

$\mathrm{t}_{o}=$ Time at which the linear phase effectively begins (hr)

$\mathrm{v}=$ Cumulative biogas production $(\mathrm{mL})$.

$\mathrm{w}=$ mass $(\mathrm{g})$

$\mathrm{X}=$ Concentration of bacterial cells $(\mathrm{mg} / \mathrm{L})$

\section{Greek Letters}

$\delta \mathrm{t}=$ Slope correction factor in the terminal phase $(\mathrm{mL} / \mathrm{hr})$

$\mu_{\mathrm{m}}=$ maximum substrate utilization rate (mgCOD/mgVSS.hr)

$\lambda=$ Lag phase period (minimum time to produce biogas) (hr). 